\title{
A simplified hysteresis current control for cascaded converter fed switched reluctance motor
}

\author{
Anuradha Devi Tellapati, Malligunta Kiran Kumar \\ Department of Electrical and Electronics Engineering, Koneru Lakshmaiah Educational Foundation, India
}

\begin{tabular}{l} 
Article Info \\
\hline Article history: \\
Received Nov 17, 2018 \\
Revised Jul 5, 2019 \\
Accepted Jul 17, 2019 \\
\hline
\end{tabular}

\section{Keywords:}

Bridge

Cascaded converter

Hysteresis current control

Switched reluctance motor

\begin{abstract}
Simple constructional features with no windings on rotor circuit and robustness make switched reluctance motor (SRM) a most used motors in industrial applications. Peak motor voltage rating depends on the rated voltage of the power switches. In conventional asymmetrical converter driving SRM, voltage rating of the motor depends on rating of power electronic switches in converter. Demand to rise the motor rating insists to put pressure on converter switching components which results in increased switching losses. A cascaded converter topology for SRM reduces the rating of switching components as compared to conventional converters for SRM. This paper presents a cascaded converter fed SRM drive with reduced switching losses. The paper presents a simplified hysteresis current control (HCC) for cascaded converter fed SRM. Simplified HCC control method reduces switching losses as HCC is applied to only one bridge of cascaded converter. Though the performance of the SRM remains same with cascaded converter fed SRM with HCC applied to only one bridge or to two bridges and with conventional asymmetrical converter, the switching losses are reduced to a great extent when HCC applied to one bridge of cascaded converter fed SRM. Performance of SRM is illustrated with conventional asymmetrical converter fed SRM and is compared to cascaded converter while HCC applied to only one bridge and applied to two bridges of cascaded converter. Proposed work is simulated using MATLAB/SIMULINK and results are presented.
\end{abstract}

Copyright (C) 2019 Institute of Advanced Engineering and Science. All rights reserved.

\section{Corresponding Author:}

Anuradha Devi Tellapati,

Department of Electrical \& Electronics Engineering,

Koneru Lakshmaiah Educational Foundation,

Vaddeswaram, Guntur, AP - 522502, India.

Email: anuradhadevi.eee@gmail.com

\section{INTRODUCTION}

Switched Reluctance Motors (SRM) have inherent advantages such as simple structure with non winding construction in rotor side, and has a high tolerances, robustness, low cost with no permanent magnet in the structure, and possible operation in high temperatures or in intense temperature variations. The torque production in switched reluctance motor comes from the tendency of the rotor poles to align with the excited stator poles. Without any installation of PM material or winding on its rotor, the SR motor drives enjoy the higher cost-effectiveness and wide-speed operation range, as compared with its counterparts. To be specific, unlike the induction and PM motor drives, SR motor drives can relieve the mechanical problems caused by the centripetal forces at high-speed operation [1-5].

The SR motor drives consist of the doubly salient structure; its reluctance of the magnetic flux path varies along the stator-rotor position. The torque can then be produced based on the 'minimum reluctance' rule, i.e. the rotor pole has the tendency to align with the excited stator pole such that the reluctance of the magnetic flux can be minimized. 
In general, the larger the number of rotor poles, the lower the operating speed in the given operating frequency. Therefore, the SR motor drives with a larger number of rotor poles, e.g. the three-phase 12/8-pole and the four-phase 16/12-pole structures, are more preferable for low-speed applications, such as the directdrive HEV system [6-10].

Three-phase 6/4 pole SRM is shown in Figure 1 and the operating principle is shown in Figure 2. To produce an electromagnetic torque, a uni-polar rectangular armature current should be injected in accordance with the status of the self-inductance with conduction angle $c=2-1$. SRM is driven with converter [11-13] for phase switching operation. Conventional asymmetrical structure converter for SRM is shown in Figure 3 is rated high for driving high power SRM. Cascaded SRM topology reduces the stress on individual power semiconductor switch in-turn reducing the switching losses. Adoption of cascaded converter topology method to the medium voltage motor drive by using cascaded inverters (CINV) method is helpful in reducing individual switch ratings of converter. CINV topology employs IGBT switch for its applications and thus cost of inverter is reduced.

This paper presents a cascaded converter fed SRM drive with reduced switching losses. The paper presents a simplified hysteresis current control (HCC) for cascaded converter fed SRM. Simplified HCC control method reduces switching losses as HCC is applied to only one bridge of cascaded converter. Though the performance of the SRM remains same with cascaded converter fed SRM with HCC applied to only one bridge or to two bridges and with conventional asymmetrical converter, the switching losses are reduced to a great extent when HCC applied to one bridge of cascaded converter fed SRM. Performance of SRM is illustrated with conventional asymmetrical converter fed SRM and is compared to cascaded converter while HCC applied to only one bridge and applied to two bridges of cascaded converter. Proposed work is simulated using MATLAB/SIMULINK and results are presented.

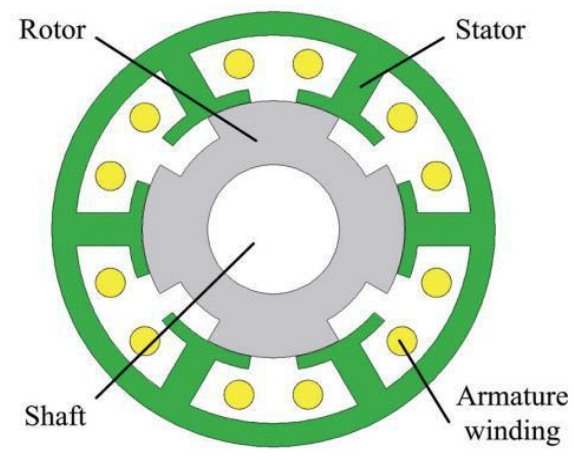

Figure 1. Three-Phase 6/4 SRM

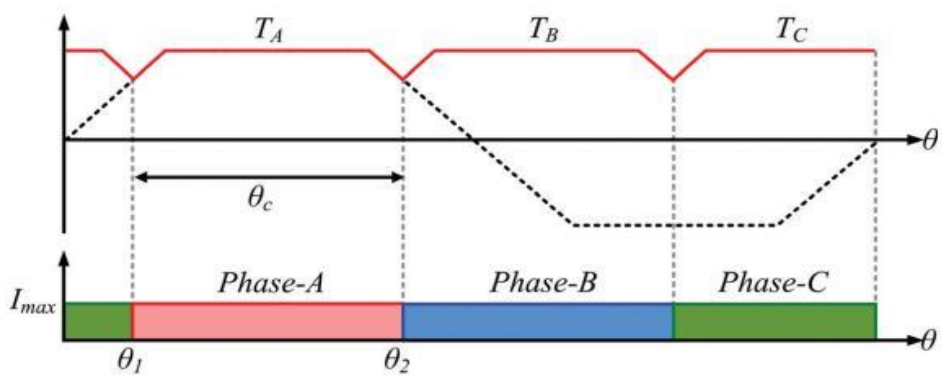

Figure 2. Operating principle of SRM

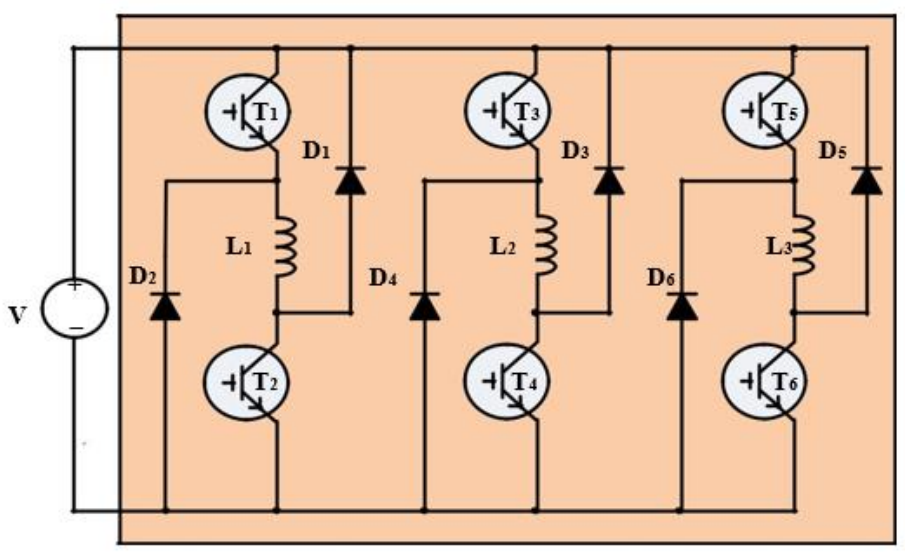

Figure 3. Conventional asymmetrical structure converter for SRM 


\section{CASCADED CONVERTER FOR SRM}

Asymmetrical converter fed SRM takes voltage stress equal to the DC source feeding the converter. Each of the two switches in one phase of asymmetrical converter is stressed to voltage level equal to the DC source feeding the converter. This phenomenon insists for higher insulation level and cost increases as a result. Also, high stress increases the switching loss in converter. Thus, research has been an interest to reduce stress across the power switches in converter driving SRM. IGBT and MOSFET are the two switches used mostly in different electrical converters for different applications. Generally IGBT's find their application in low operating frequency with high voltage application while MOSFET find their application in high operating frequency with low voltage application. Conventional converters for SRM are of high rated and need high rated switches for converter operation which increases the switch losses.

\section{Proposed SRM cascaded converter}

Cascaded converter topology consists of one main converter and auxiliary converter. Two converters are cascaded and the output is fed from combined cascaded structure. As shown in Figure 4, one phase of cascaded inverter consists of two H-Bridges cascaded and the output of the phase for phase excitation of SRM is fed from combined cascaded structure topology. Only one phase explanation is illustrated as one phase operation replicates the operation of remaining other phases of SRM as they are independent in operation. Load voltage is dependent on the output of each cascaded converter of SRM. A cascaded structural cascaded converter for SRM impresses only half the voltage of load across power switch. Thus, in case of using same rated voltage switching device with the conventional circuit, the load voltage becomes twice. Figure 5 represents one-phase representation of Cascaded converter.

Figure 6 shows the operational modes of proposed cascaded converter for SRM. The voltage at phase winding of SRM in different operating modes of cascaded converter is represented in Table 1. In this context, only the phase operation of phase- $\mathrm{A}$ is explained and the same modes of operations are applicable for other two phases also. The operational modes of cascaded inverter gives out five level output. Mode I as shown in Figure 6(a) gives out the voltage of +Vdc. In mode I, switches Sa1 - Sa2 - Sb1 and Sb2 are turned ON. The current flows from source through the current path as shown in Figure 6(a) highlighted path adding the two voltage sources. In this case all the diodes as in OFF state. Mode II of cascaded converter operation yields output of Vdc/2. In mode II, the switches Sa1 - Sa2 and Sb2 are turned ON while switch $\mathrm{Sb1}$ is OFF. Current path is shown in Figure 6(b). This mode of operation does not involve the lower DC source. Mode III is represented in Figure 6(c) and only the upper bridge switches Sa1 and Sa2 are ON while other switches are inactive. The current flows from upper DC source and enters lower DC source in opposite direction cancelling out the net voltage and thus the mode-III gives out zero output voltage across load. Mode IV and mode $\mathrm{V}$ operates to give out negative voltage presence across load and the respective current paths are shown in Figure 6(d) and Figure 6(e) respectively. By turning ON respective switches and diode operations, negative voltage is impressed across load.

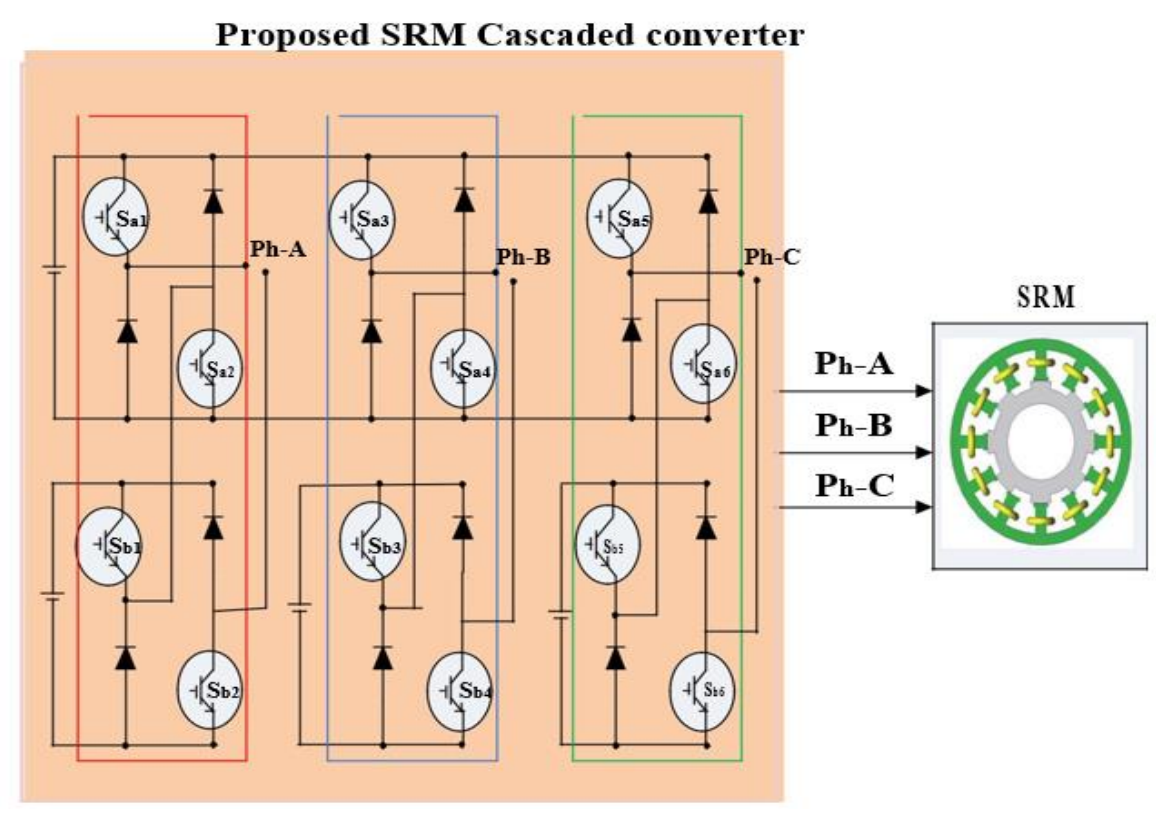

Figure 4. Cascaded converter fed SRM 


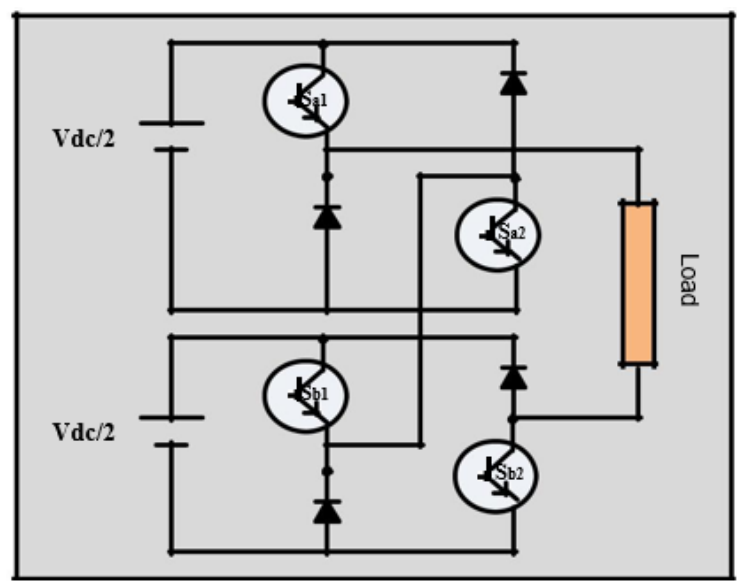

Figure 5. One phase representation of cascaded converter

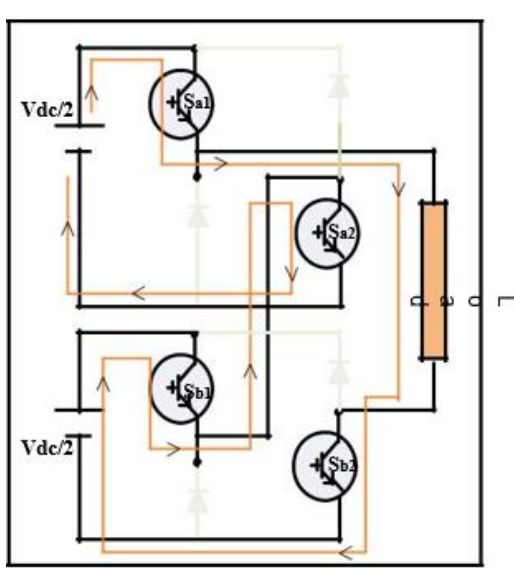

(a)

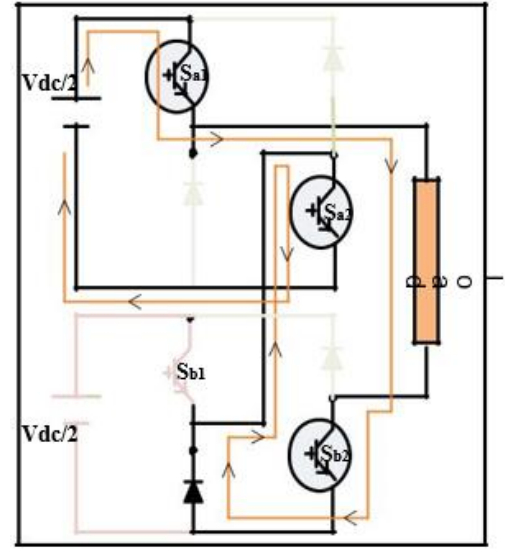

(b)

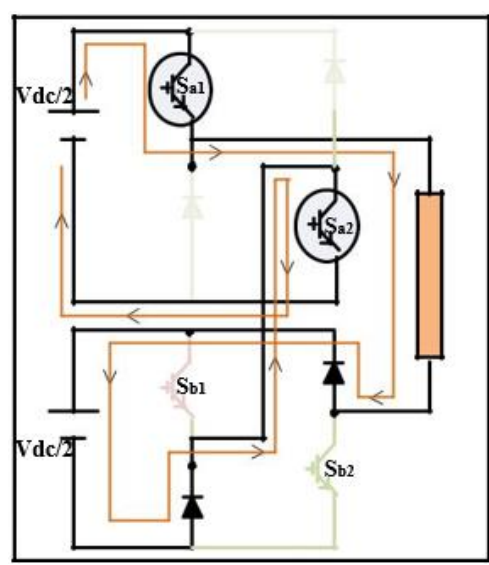

(c)

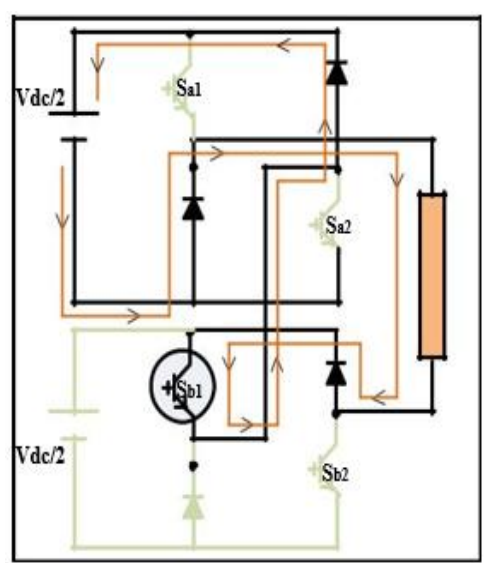

(d)

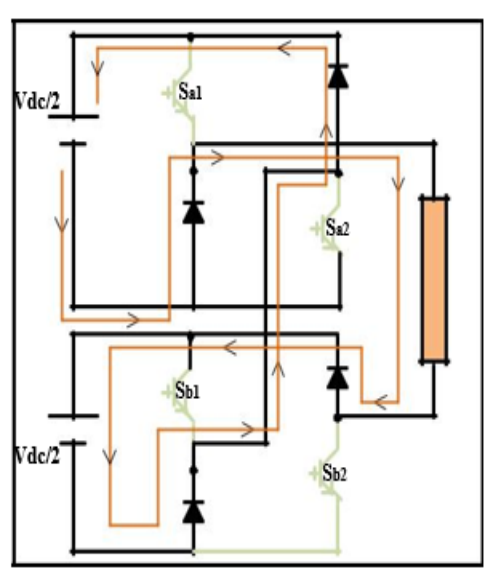

(e)

Figure 6. Modes of operation of cascaded converter

In conventional asymmetrical type of converter for SRM, the voltage across each switch will be the equal to total voltage source value. If $200 \mathrm{~V}$ is applied as input DC source voltage, each switch bears the voltage stress of $200 \mathrm{~V}$ and the insulation and rating of switch should be proportional to voltage stress across switch and thus increasing the stress and cost. But the cascaded inverter topology exhibits the stress of $100 \mathrm{~V}$ across each switch due to converter topology. In cascaded converter topology, half the voltage stress is reduced and thus the rating of the switch and insulation reduces reducing the losses and cost. 
Table 1. Modes of cascaded converter with voltage levels

\begin{tabular}{ccc}
\hline Mode of Operation & Switches ON & Voltage Level across load \\
\hline Mode I & $\mathrm{Sa} 1, \mathrm{Sa} 2, \mathrm{Sb} 1, \mathrm{Sb} 2$ & $+\mathrm{Vdc}$ \\
Mode II & $\mathrm{Sa} 1, \mathrm{Sa} 2, \mathrm{Sb} 2$ & $+\mathrm{Vdc} / 2$ \\
Mode III & $\mathrm{Sa} 1, \mathrm{Sa} 2$ & 0 \\
Mode IV & $\mathrm{Sb} 1$ & $-\mathrm{Vdc} / 2$ \\
Mode V & $\mathrm{Nil}$ & $-\mathrm{Vdc}$ \\
\hline
\end{tabular}

\section{PROPOSED SIMPLIFIED CONTROL OF CASCADED CONVERTER}

\section{a. Closed-loop hysteresis current control for conventional asymmetrical converter}

Figure 7 illustrates the closed-loop speed control of conventional asymmetrical Converter for SRM. Speed control is achieved through the information received from rotor position signal receiver and the actual speed is also fed back to the input for precise speed control in closed-loop speed control. Actual speed of the rotor is sensed and is compared to the reference speed value to give out the error in speed.

The error value is fed to PI controller to yield magnitude of the current signal. The angular velocity of the rotor sensed from hall sensors is used to obtain current shape when passed through rotor position signal receiver. Current shape signal is multiplied to current magnitude signal obtained from PI controller output to obtain reference current signal. Reference current is compared with the actual current from stator currents and the error signal is sent to hysteresis current controller. Hysteresis current controller (HCC) produces gate pulses to all the six power switches in asymmetrical converter to excite the phase windings of SRM. Closed - loop speed control strategy yields better and precise control of SRM.

\section{b. Closed-loop control of cascaded converter (hysteresis current control applied to both upper and lower bridges)}

Figure 8 illustrates the closed-loop speed control of cascaded converter where hysteresis current control produces gate pulses to power switches of cascaded converter. The hysteresis current control generates gate pulses to all the twelve switches of cascaded converter. Cascaded converter is a cascaded connection of two bridges: the upper bridge and the lower bridge. Each bridge consists of six switches forming Sa1 to Sa6 upper bridge and $\mathrm{Sb} 1$ to Sb6 lower bridge.

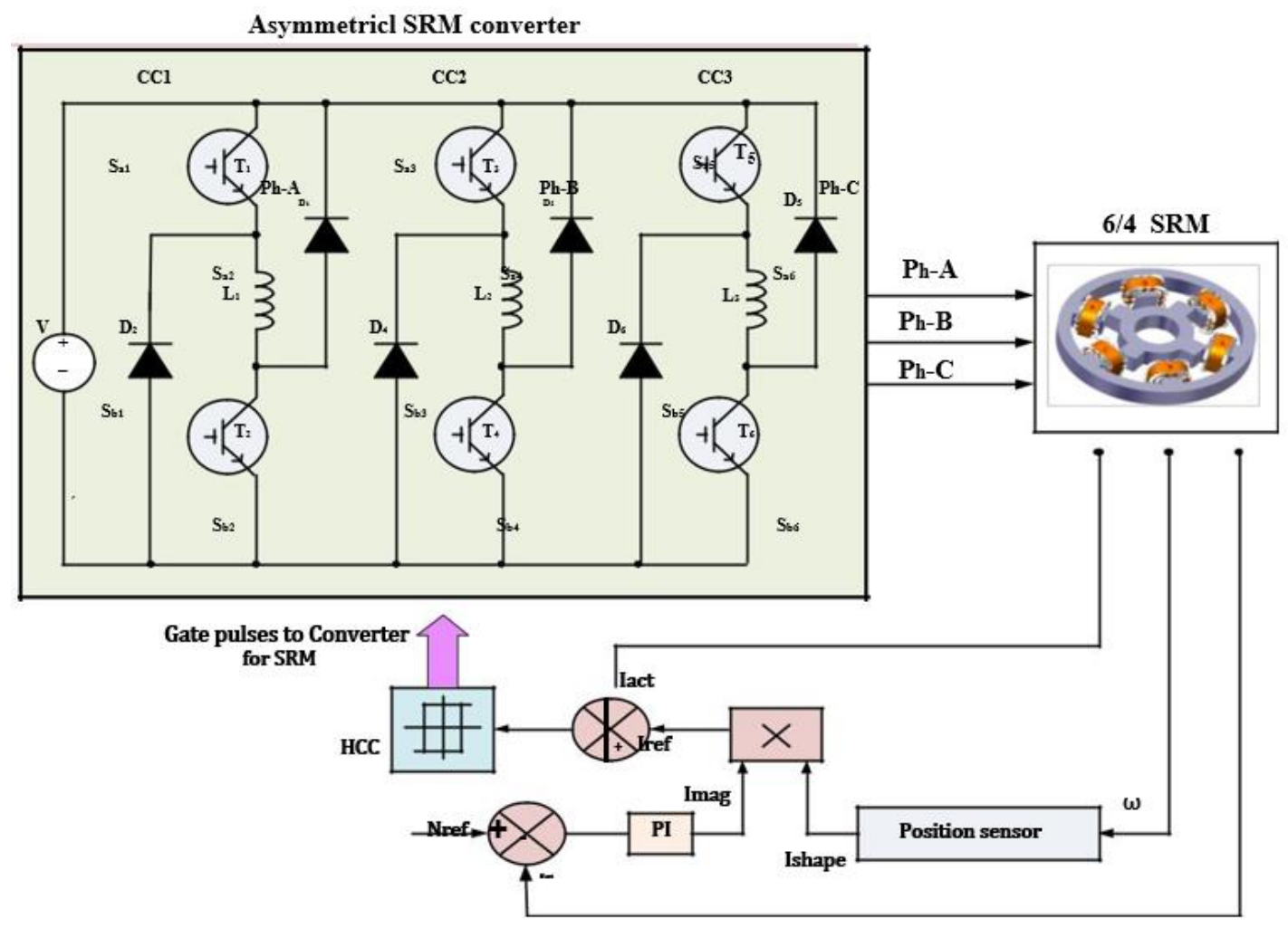

Figure 7. Closed-loop hysteresis current control for conventional asymmetrical converter 


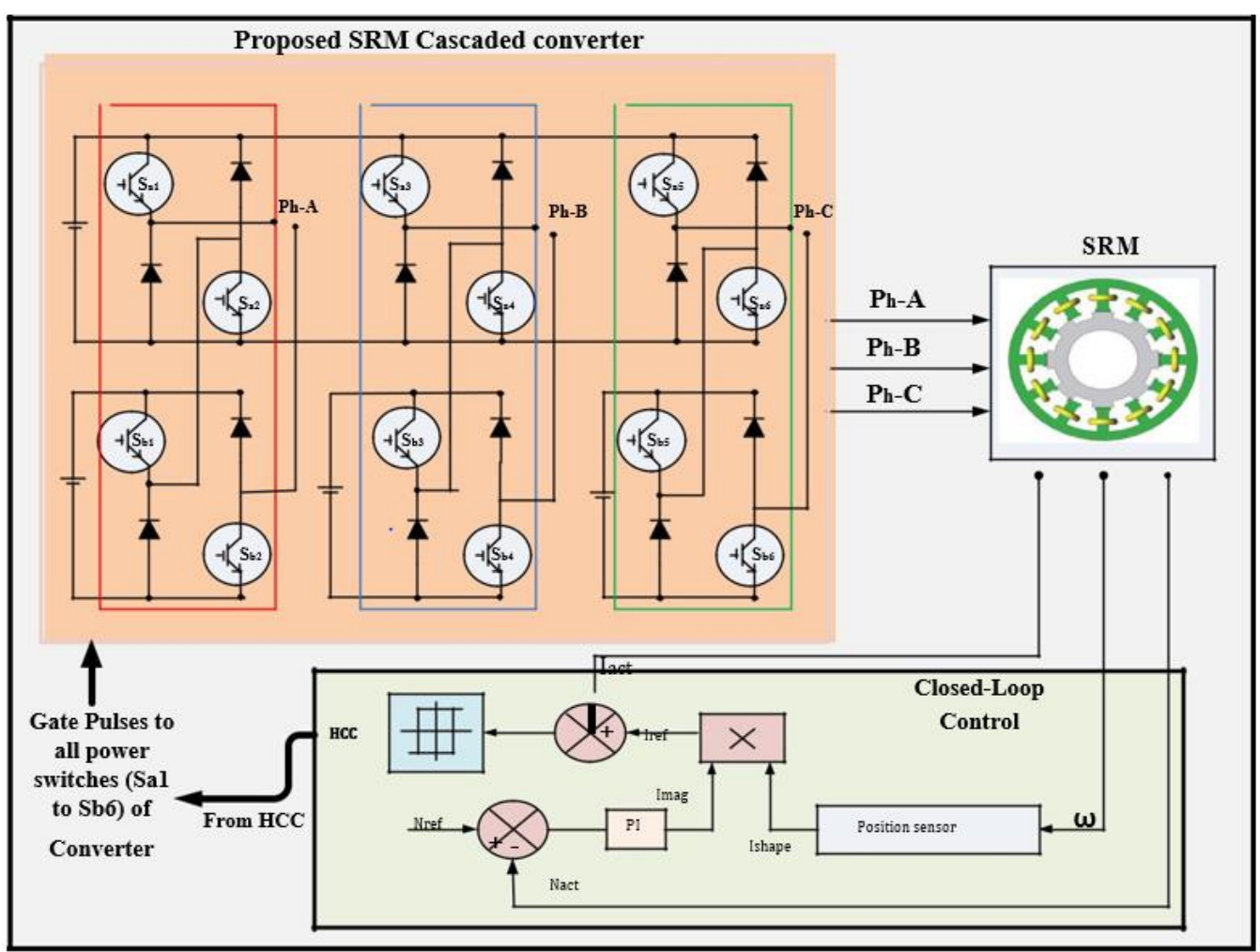

Figure 8. Closed-loop control of cascaded converter HCC applied to both the bridges

Actual speed of the rotor is sensed and is compared to the reference speed value to give out the error in speed. The error value is fed to PI controller to yield magnitude of the current signal. The angular velocity of the rotor sensed from hall sensors is used to obtain current shape when passed through rotor position signal receiver. Current shape signal is multiplied to current magnitude signal obtained from PI controller output to obtain reference current signal. Reference current is compared with the actual current from stator currents and the error signal is sent to hysteresis current controller (HCC).

The output of hysteresis control is fed to all the twelve switches (both upper and lower bridges) of cascaded converter. With the cascaded structure of cascaded converter, the voltage stress across each switch reduces by half the quantity when compared to the conventional asymmetrical converter. With HCC driving all the switches (both upper bridge and lower bridge) of cascaded converter, all the twelve switches are turned-ON and OFF multiple times. With this phenomenon of turning ON and OFF multiple times, switching losses increases. This leads to development of simplified HCC for cascaded converter.

\section{c. Closed-loop control of cascaded converter (hysteresis current control applied to only upper bridge alone)}

Figure 9 illustrates the closed-loop speed control of cascaded converter where hysteresis current control produces gate pulses to only power switches of upper bridge of cascaded converter. Actual speed of the rotor is sensed and is compared to the reference speed value to give out the error in speed. The error value is fed to PI controller to yield magnitude of the current signal. The angular velocity of the rotor sensed from hall sensors is used to obtain current shape when passed through rotor position signal receiver. Current shape signal is multiplied to current magnitude signal obtained from PI controller output to obtain reference current signal. Reference current is compared with the actual current from stator currents and the error signal is sent to hysteresis current controller (HCC).

HCC generated gate pulses are fed only to upper bridge (six) power switches alone and the lower bridge (six) power switches are driven by current shape signals obtained from position sensor. With respect to their switching times, upper bridge (six) switches are turned ON and OFF multiple times since they are driven from HCC while lower bridge (six) switches remain continuously in ON state or OFF state over a period of time. This method of triggering switches reduces overall switching losses due to ON and OFF conditions. 


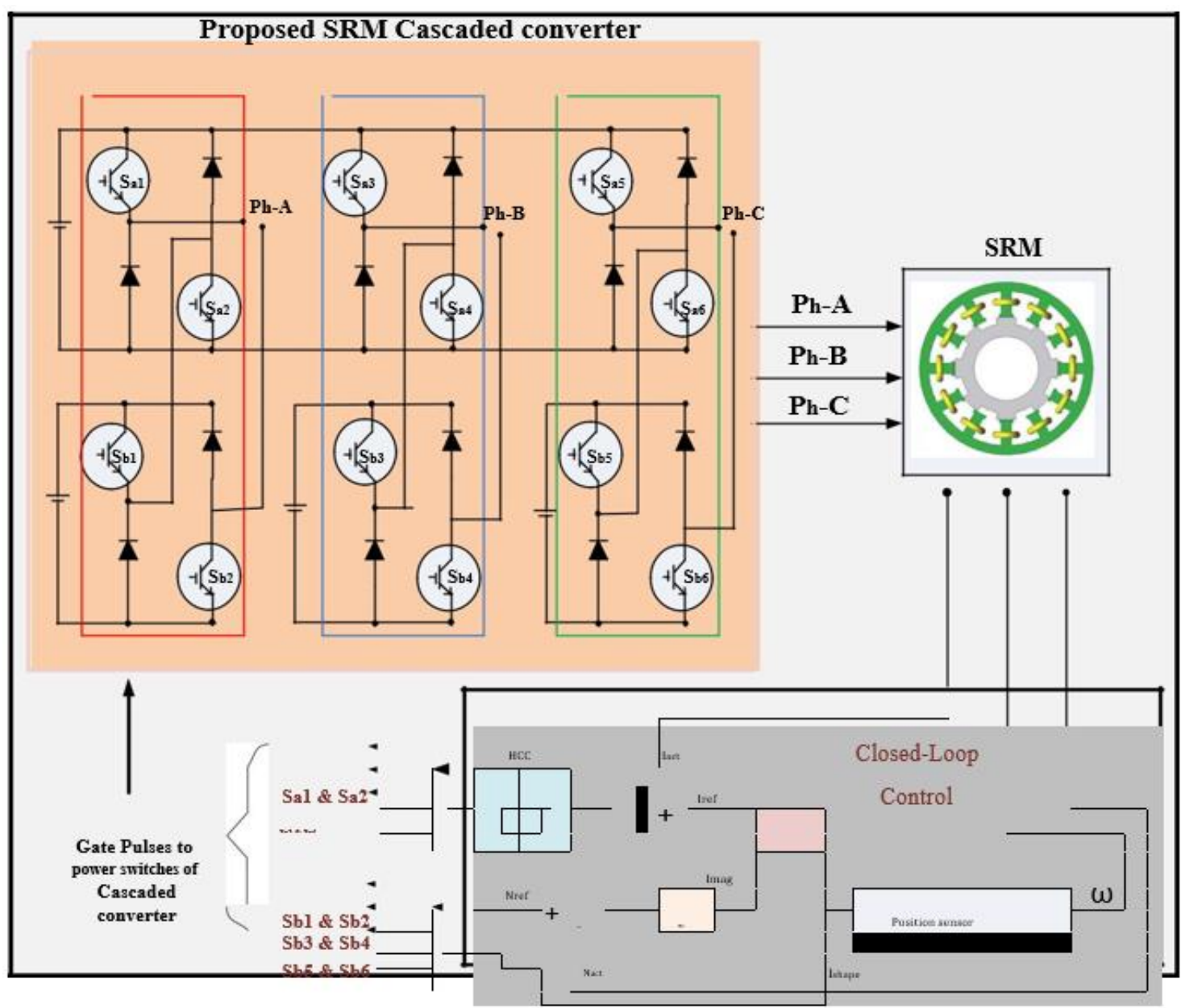

Figure 9. Closed-loop control of cascaded converter HCC applied to only one (upper) bridge

\section{RESULTS AND ANALYSIS}

a. Performance analysis of conventional asymmetrical converter fed SRM

Figure 10 shows the stator current, torque and speed of asymmetrical converter fed SRM. Stator of SRM draws 20A peak currents from the converter for the excitation of phase windings. Torque contains ripples. SRM runs at constant 2000RPM as shown in figure.

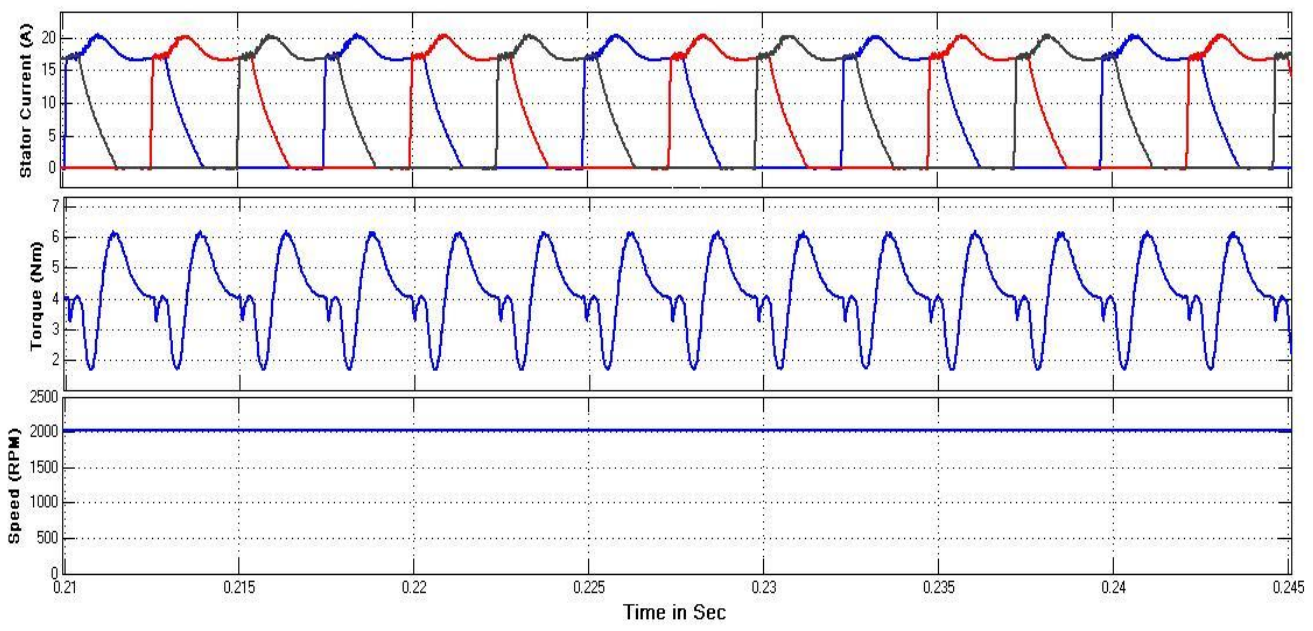

Figure 10. Performance characteristics of asymmetrical converter fed SRM 
Figure 11 illustrates the voltage stress across one switch of cascaded converter, phase output voltage of cascaded converter. Zoom-in view of voltage stress across switch and phase voltage is shown. Each switch is subjected to voltage stress of $200 \mathrm{~V}$ and the phase output voltage is $200 \mathrm{~V}$ peak. The switching pattern with respect to stator current is shown in Figure 11.when the phase is excited, each switch is stressed up to 200V giving out phase voltage of $200 \mathrm{~V}$ (peak value) in cascaded converter. In this case, when SRM is driven by asymmetrical converter, each switch is stressed up to phase voltage value.

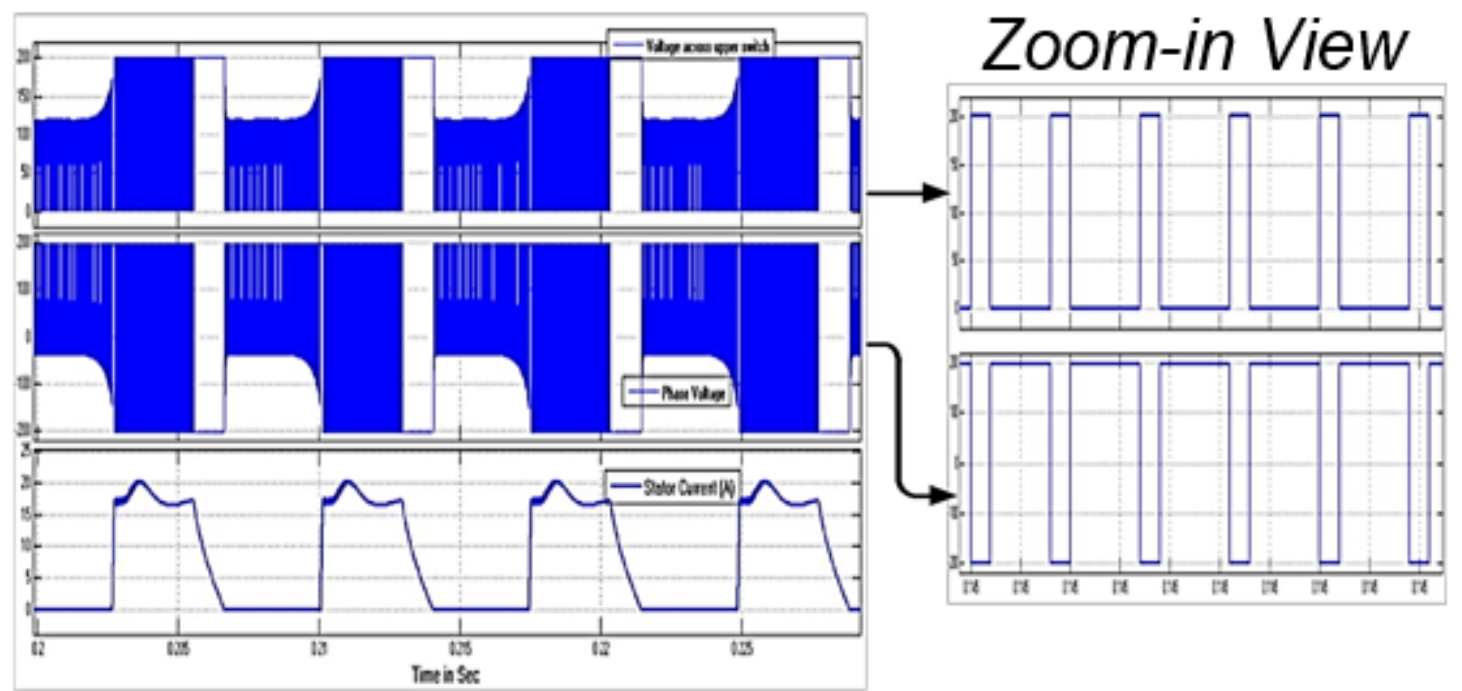

Figure 11. Voltage across switch, phase voltage and currents (to SRM) in cascaded converter

\section{b. Sub section performance analysis of cascaded converter fed SRM (HCC driving both upper and} lower bridges)

Figure 12 shows the stator current, torque and speed of cascaded converter fed SRM. Stator of SRM draws 20A peak currents from the converter for the excitation of phase windings. Torque contains ripples. SRM runs at constant 2000RPM as shown in figure. Closed-loop operation makes machine to run at constant speed.

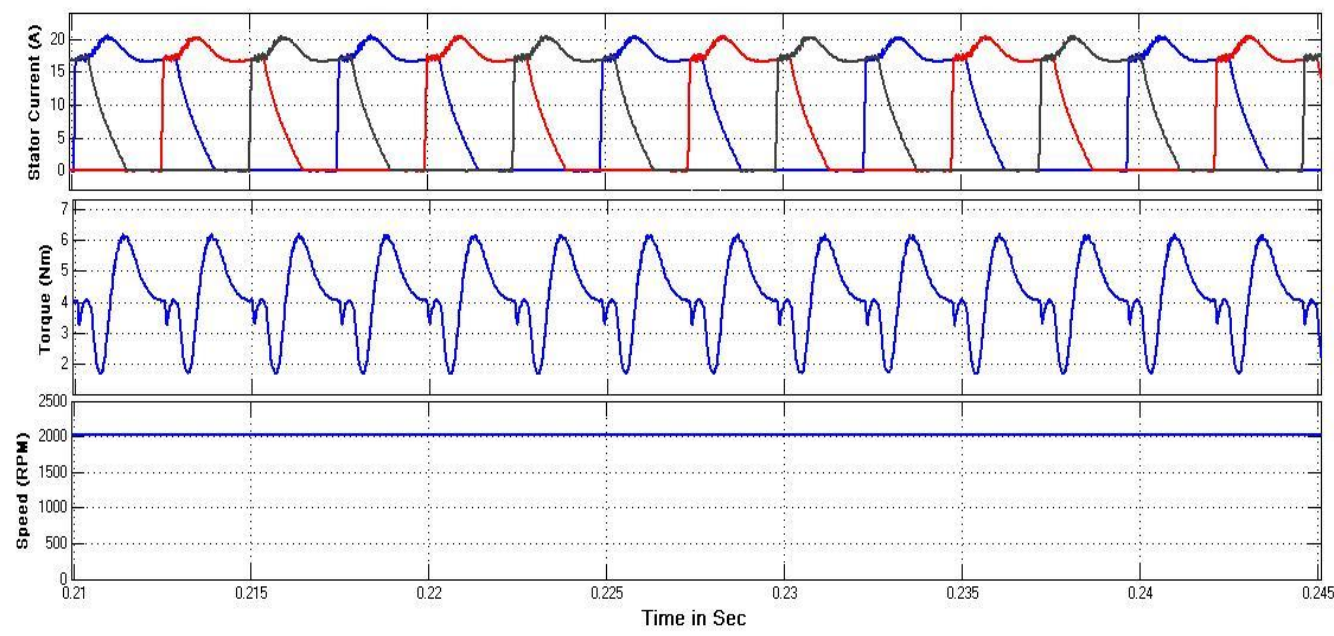

Figure 12. Performance characteristics of cascaded converter fed SRM (HCC driving both upper and lower bridges) 
Figure 13 illustrates the voltage stress across one switch (upper bridge) of cascaded converter, phase output voltage of cascaded converter. Switching periods for respective phase excitation (phase excitation) is also indicated in figure. Voltage stress across one switch (lower bridge) of cascaded converter is also indicated in Figure 13. Each switch (both upper and lower bridge) is subjected to voltage stress of $100 \mathrm{~V}$ and the phase output voltage is $200 \mathrm{~V}$ peak. When the phase is excited, each switch is stressed up to $100 \mathrm{~V}$ giving out phase voltage of $200 \mathrm{~V}$ (peak value) in cascaded converter. In this case, when SRM is driven by cascaded converter, each switch is stressed up to only half the amount of phase voltage value. Zoom-in view of voltage stress across upper bridge and lower bridge switch is shown in Figure 14 showing voltage stress of 100V across each switch. When HCC drives both upper and lower switches of converter, both upper bridge switches and lower bridge switches are turned ON and OFF multiple times per cycle. This increases the switching losses in converter. Though voltage stress is reduced, switching losses increases due to multiple turn $\mathrm{ON}$ and OFF's.
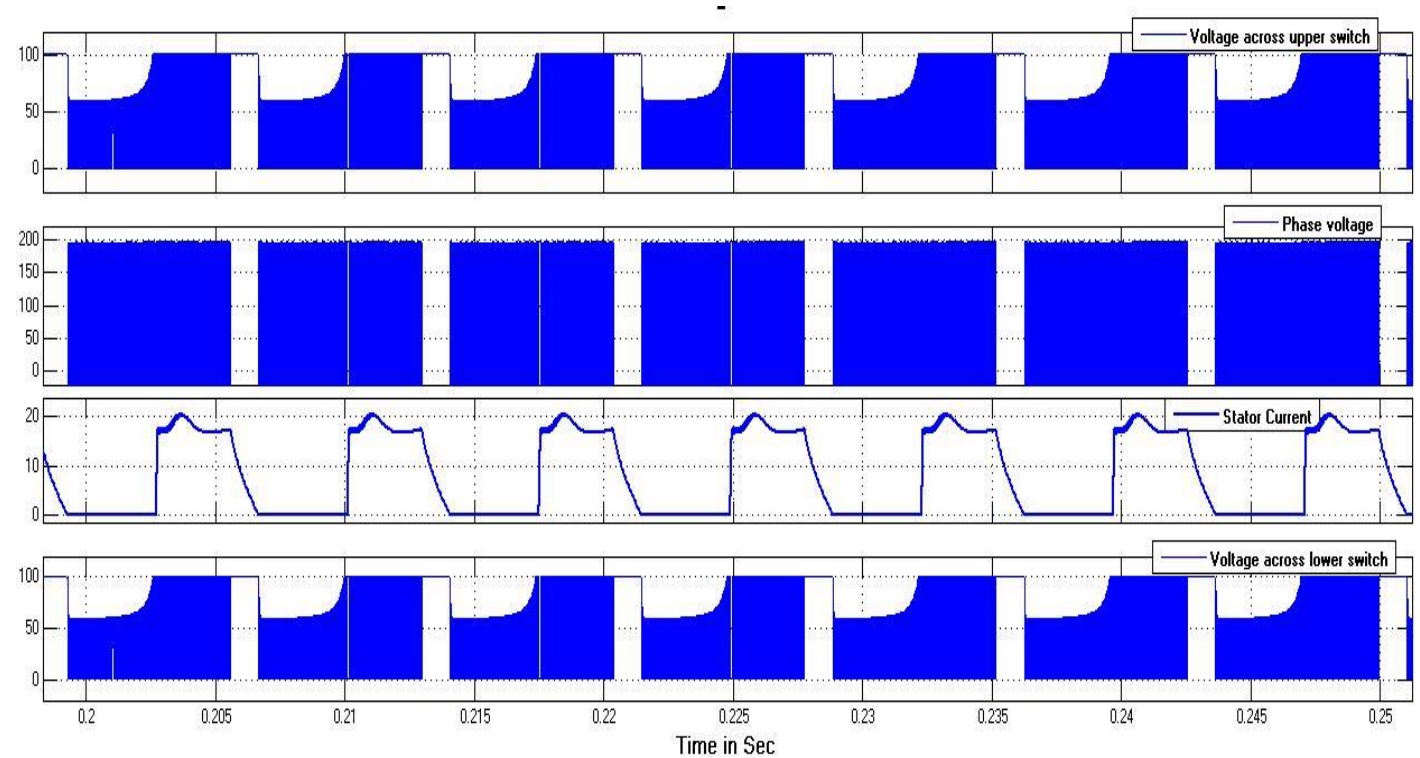

Figure 13. Voltage across upper switch, phase voltage, currents (to SRM) and voltage across lower switch in cascaded converter
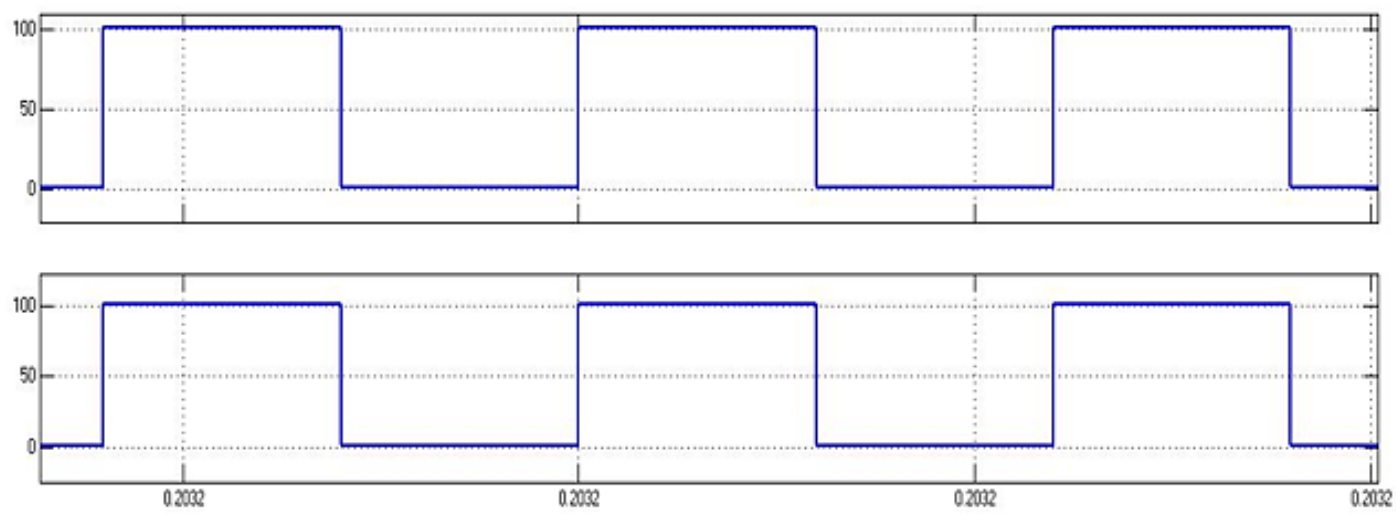

Figure 14. Zoom-in view of voltage stress across upper bridge and lower bridge switch

\section{c. Performance analysis of cascaded converter fed SRM (HCC driving only upper bridge)}

Figure 15 shows the stator current, torque and speed of cascaded converter fed SRM. Stator of SRM draws 20A peak currents from the converter for the excitation of phase windings. Torque contains ripples. SRM runs at constant 2000RPM as shown in figure. Closed-loop operation makes machine to run at constant speed.

A simplified hysteresis current control for cascaded converter fed switched ... (Anuradha Devi Tellapati) 


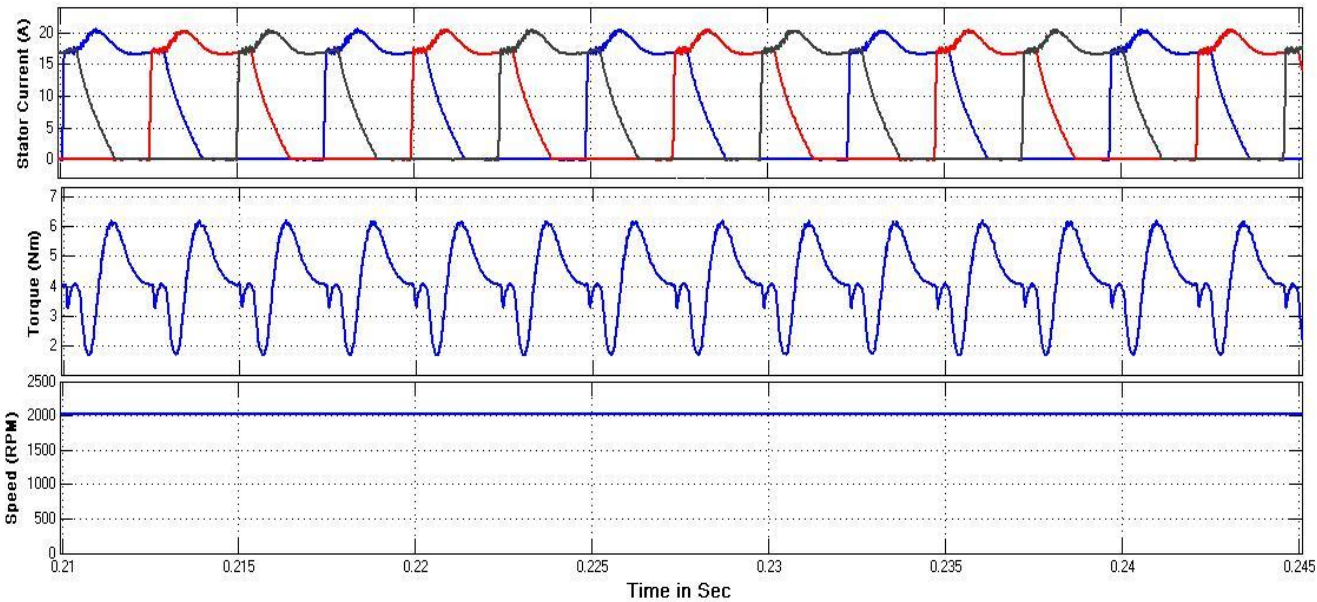

Figure 15. Performance characteristics of cascaded converter fed SRM (HCC driving only upper bridge)

Figure 16 illustrates the voltage stress across one switch (upper bridge) of cascaded converter, phase output voltage of cascaded converter. Switching periods for respective phase excitation (stator current) is also indicated in figure. Voltage stress across one switch (lower bridge) of cascaded converter is also indicated in Figure 16. Each switch (both upper and lower bridge) is subjected to voltage stress of $100 \mathrm{~V}$ and the phase output voltage is $200 \mathrm{~V}$ peak. When the phase is excited, each switch is stressed up to $100 \mathrm{~V}$ giving out phase voltage of $200 \mathrm{~V}$ (peak value) in cascaded converter. In this case, when SRM is driven by cascaded converter, each switch is stressed up to only half the amount of phase voltage value.

Zoom-in view of voltage stress across upper bridge and lower bridge switch is shown in Figure 17 showing voltage stress of $100 \mathrm{~V}$ across each switch. When HCC drives only upper switches of converter, multiple turn ON and OFF per cycle are observed in only upper switch while lower switch continuously turns $\mathrm{ON}$ or OFF which is clearly indicated in Figure 17. This phenomenon decreases the switching losses in converter when compared to HCC driving both bridges.

Though the performance characteristics remains same in comparing asymmetrical and cascaded converter (in two modes), switching losses (turn ON and OFF) are reduced in case when HCC drives only upper switches of converter. Figure 18 illustrates difference of analysis with cascaded and conventional converter in bar representation. Bar representation of switching (Turn ON \& OFF) losses is shown in Figure 19.
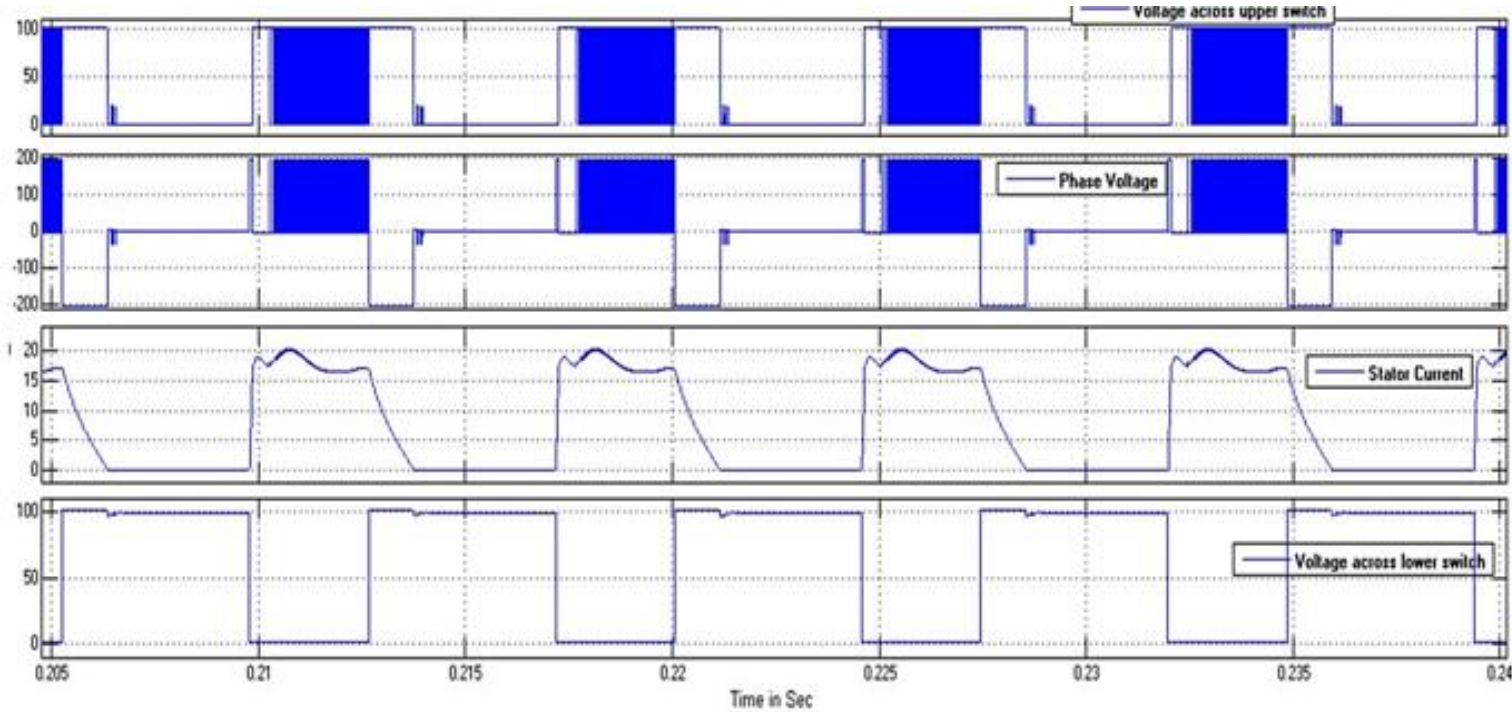

Figure 16. Voltage across upper switch, phase voltage, currents (to SRM) and voltage across lower switch in cascaded converter 

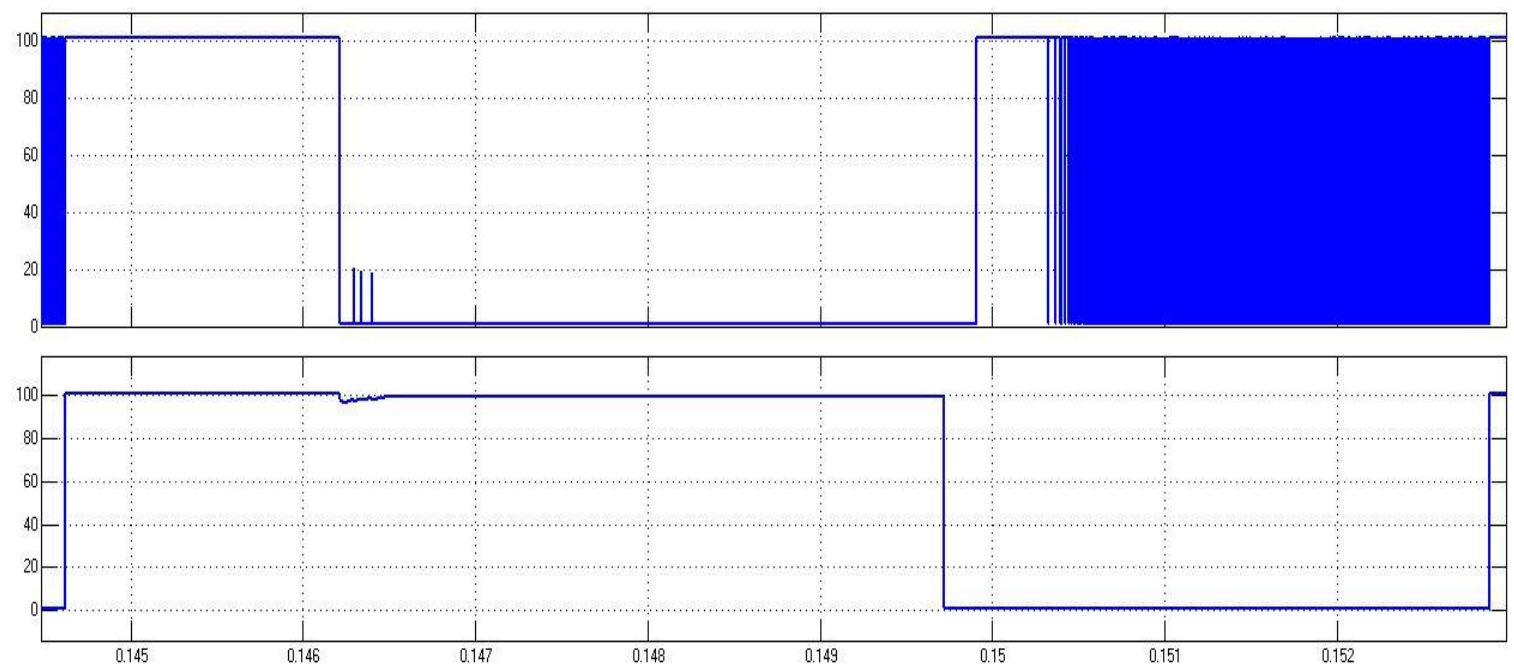

Figure 17. Zoom-in view of voltage stress across upper bridge and lower bridge switch

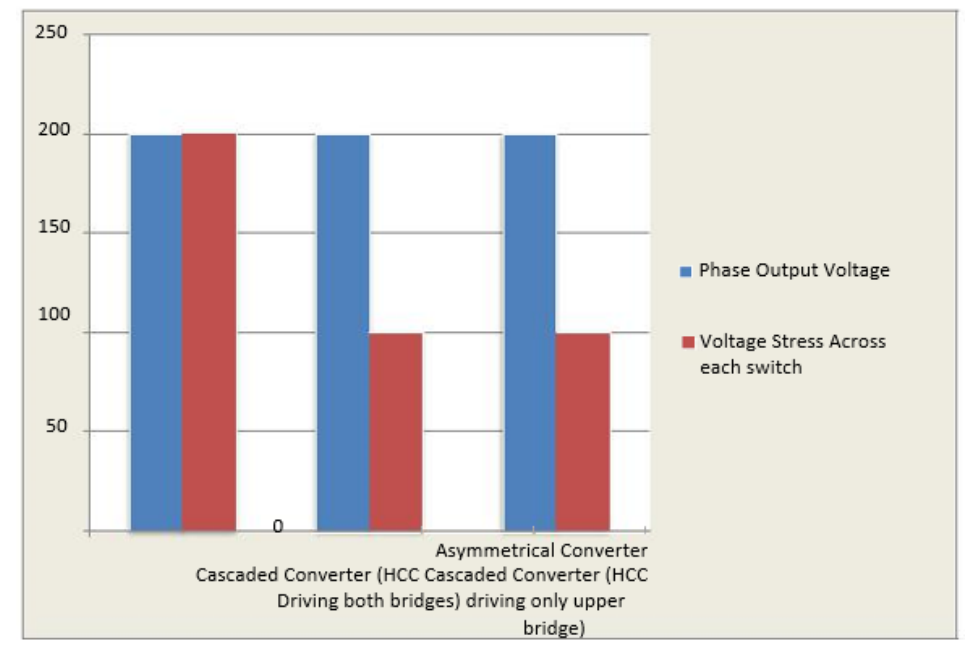

Figure 18. Voltage stress bar representation in different converter operations

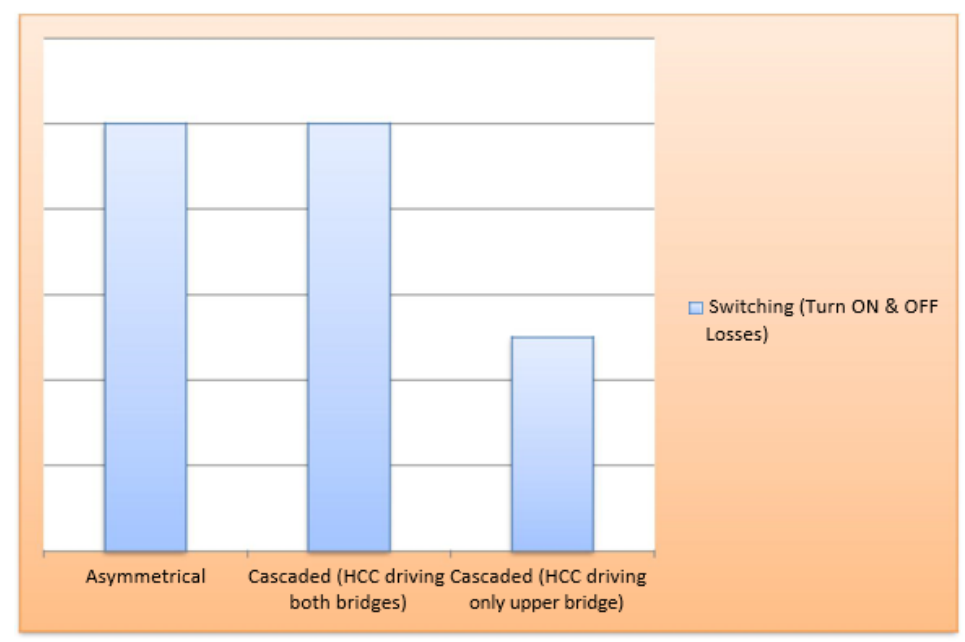

Figure 19. Bar representation of switching (Turn ON \& OFF) losses 


\section{CONCLUSION}

Efficiency, robust construction, speed-torque characteristics and efficiency with high speed operations makes SRM to take an edge over other conventional motors in many applications. This paper presents a cascaded converter fed SRM drive with reduced switching losses. The paper presents a simplified hysteresis current control (HCC) for cascaded converter fed SRM. Simplified HCC control method reduces switching losses as HCC is applied to only one bridge of cascaded converter. Though the performance of the SRM remains same with cascaded converter fed SRM with HCC applied to only one bridge or to two bridges and with conventional asymmetrical converter, the switching losses are reduced to a great extent when HCC applied to one bridge of cascaded converter fed SRM. When HCC drives only upper switches of converter, multiple turn ON and OFF per cycle are observed in only upper switch while lower switch continuously turns $\mathrm{ON}$ or OFF and decreases the switching losses in cascaded converter when compared to HCC driving both bridges.

\section{REFERENCES}

[1] Praveen Vijayraghavan, "Design of switched reluctance motors and development of a universal controller for switched reluctance and permanent magnet brushless DC motor drives," Dissertation submitted to Virginia Polytechnic Institute and State University, Blacksburg, Virginia, Nov 2011.

[2] T. J. E. Miller, Switched reluctance motors and their control, Magna Physics \&Oxford, 1993.

[3] Rik De Doncker, Duco W. J. Pulle and Andre Veltman, "Advanced electrical drives: analysis, modeling and control," Springer,2011.

[4] R. Krishnan, "Design and development of low-cost and highefficiency variable-speed drive system with switched reluctance motor," IEEE Trans.,Ind. Appl., vol. 43(3), May/Jun 2007.

[5] Sihem Saidani, Mohamed Radhouan Hachicha, Moez Ghariani, "A new phase current profiling with FLC for torque optimization of 12/8 SRM," International journal of Electrical and Computer Engineering (IJECE), vol. 6(5), pp. 1948-1955, Oct 2016.

[6] R. Krishnan, "Switched reluctance motor drives-modeling, simulation, analysis drives, applications," CRC press.

[7] Adrian David Cheok and Yusuke Fukuda, "A new torque and flux control method for switched reluctance motor drives," IEEE Trans., on Power Electronics., vol. 17(4), pp. 543, July 2002.

[8] H. Akagi, "Classification, terminology, and application of the modular multilevel cascade converter (MMCC)," IEEE, Trans. on Power Electronics, vol. 26(11), pp. 3119-3130, Nov 2011.

[9] M. Marchesoni and M. Mazzucchelli, "Multilevel converters for high power ac drives: A review," in Conf. Rec. IEEE Int. Symp. Ind. Electron, pp. 38-43, 1993.

[10] Ibrahim Farouk Bouguenna, Ahmed Azaiz, Ahmed Tahour, Ahmed Larbaoui "Hybrid fuzzy sliding mode speed control for an electric vehicle drive," International journal of power electronics and drive system (IJPEDS), vol. 8(3), pp. 1050-1061, Sep 2017.

[11] H. Akagi, S. Inoue, and T. Yoshii, "Control and performance of a transformerless cascade PWM STATCOM with star configuration," IEEE Trans. Ind. Appl., vol. 43(4), pp. 1041-1049, Jul./Aug. 2007.

[12] R.Matsui, "Torque/current ratio improvement and vibration reduction of switched reluctance motors using multistage structure," IEEE. IPEC2014., pp. 1128-1134, May. 2014.

[13] S. Vukosavic and V. R. Stefanovic, "SRM inverter topologies: A comparative evaluation," IEEE Trans. Ind. Appl., vol. 27(6), pp. 1034-1047, Nov./Dec. 1991. 